\title{
Guest Editorial: Special Issue on Sustainability and Libraries
}

As we are writing this introduction, we are thinking a lot about COVID-19 and how it has impacted our lives, our work and our environment. We think about the future, and what awaits with COVID19 and the efforts of sustainability. Today, we know that libraries and all library workers are greatly affected and concerned by issues connected to sustainability. From environmental to social to financial sustainability, we need to re-center our focus on what changes we can make and how to share progress.

We are seeing the rise of climate refugees across the world being affected by the climate crisis. Libraries can play a role in informing users and communities about such issues (Hawco, 2019). We can think about the United Nations and its Sustainable Development Goals (SDGs) and how all library workers can align their work to the SDGs and foster awareness of resources and developments in their communities that they serve. More importantly, we need to start having these conversations now and implementing such plans and to raise awareness of our own social responsibilities and accountabilities to the environment that is impacting life.

In this special issue, we, as the co-guest editors, wanted to focus on international efforts related to sustainability in libraries. We aimed to collect and showcase global voices and stories from what library workers of all types (academic, public, school, special, etc) were doing to support sustainability efforts. In this issue, our five featured articles, two reports from the field and one library association report were selected to offer a global perspective on the issue of sustainability and libraries today.

In Brazil, researchers Genilson Geraldo and Marli Dias de Souza Pinto found the use of Instagram, the social networking app, to be an effective communication tool to promote sustainability issues to users. Through the concept of informational sustainability, sustainable development information can be shared in social networks to be made available to 4000 followers. They analyzed the use of this tool to disseminate sustainable information through libraries.

In Australia, librarian Roxanne Missingham shared how the Australian university libraries meet UN SDGs and came up with a model that integrated assessment of sustainability to generate useful insights on the value of libraries. In the United States, librarians Jennifer Embree and Neyda V. Gilman offered a case study on campus sustainability practices through the academic library. Their academic library presented an opportunity to support campus sustainability through university-wide engagements and collaborations.

In Sri Lanka, librarians Damaynathi Gunasekera and Manori Samarakoon highlighted the sustainable development project initiated by the Buddhist and Pali University of Sri Lanka in mid2019. The project shared how to increase sustainability awareness and practices in this university and engage with their community of users through training, workshops and other resource developments. In Kazakhstan, librarians Joseph Yap and April Manabat shared how Nazarbayev University Library adjusted to environmental practices during the pandemic. They discussed how 
they have implemented sustainable work from their "working from home" situation during the pandemic.

In the reports from the field and a commentary, we have contributors from Finland, Hong Kong and the United States. For reports, in Finland, a team of library professionals and advocates Ulla Pötsönen, Harri Sahavirta and Leila Sonkkanen collaborated to describe how public libraries support and promote sustainability efforts. They explored the current situation of public libraries in supporting sustainability in Finland through a variety of projects, surveys and assessments. Librarian Leo Ma from the Chinese University of Hong Kong shared and reflected on how the conference, "Sustainable Academic Libraries: Now and Beyond" co-organized by the Hong Kong University of Science and Technology Library and the Chinese University of Hong Kong Library provided an opportunity for academic libraries to discuss and share sustainability plans collectively.

In a commentary, the American Library Association's (ALA) UN 2030 SDG task force members from the United States Loida Garcia-Febo and Robin Kear shared how ALA planned for its UN 2030 SDG task force and its work in aligning ALA under SDG. They highlighted events, webinars and upcoming programs and resources to engage with the global library community.

This special issue highlighted diverse voices and perspectives across five continents and seven countries. These projects showcased how sustainability is truly a global community issue for all. We have an opportunity to share and implement equitable and sustainable practices for and in our profession, associations, workplaces and communities-at-large. When we all work together and hold ourselves and each other accountable, we can collectively address and promote environmental justice for all before it is too late.

In addition, we like to thank all contributors for taking the time to write and document their sustainability efforts for this special issue, particularly during COVID-19. We like to acknowledge the IJoL Chief Editor Grace Liu for her guidance, support and prompt responses! We also like to thank copy editors of IJoL for their time and work. We also thank our copy editors: Xiaoai Ren, Cecilia Tellis, Jessica Koos, and Helen Power, and lay out editors: Cindy Li and Gordon Xu for making this special issue possible!

This special issue was reviewed by numerous external peer reviewers and we would like to acknowledge and thank them for their time and service to the community: Amani Magid, Angela A. J. Kent, Hiromi Kubo, Michael Gutierrez, Sophia Sotilleo, Leyla Cabugos, Nicollette Davis, Estella Terrazas, and Jana de Brauwere. Along with copyeditors, our reviewers provided helpful comments and feedback to each paper. We hope you enjoy this special issue and find inspiration!

\title{
Raymond Pun, Alder Graduate School of Education, United States
}

\author{
Ulla Pötsönen, Independent Library Advocate, Community Educator, Finland
}




\section{Reference}

Hawco, C. (2019). Transforming Public Libraries as Spaces of Refuge \& Resiliency During Climate Crisis: Toronto Public Library Youth and Staff Perspectives. (unpublished master's thesis). York University, Toronto, Canada. Retrieved from https://yorkspace.library.yorku.ca/xmlui/bitstream/handle/10315/36901/MESMP02883.pdf?sequ $\underline{\text { ence }=1}$

\section{Editing contributors to this issue}

Copy Editing: Xiaoai Ren, Jessica Koos, Cecilia Tellis, and Helen Power

Layout Editing: Cindy Li and Gordon $\mathrm{Xu}$ 